\title{
Sistem Monitoring Tingkat pH, Kekeruhan dan Suhu Air Limbah Batik pada Instalasi Pengolahan Air Limbah Berbasis LoRa
}

\section{The Monitoring System of Batik Industry Waste Water $\mathrm{pH}$, Turbidity, and Temperature on The Water Treatment Installation based on LoRa}

\author{
Mohamad Abdul Jalil Faza ${ }^{1, *}$, Sevia Indah Purnama², Fikra Titan Syifa ${ }^{3}$ \\ ${ }^{123}$ Program Studi S1 Teknik Telekomunikasi, \\ Fakultas Teknik Telekomunikasi dan Elektro, Institut Teknologi Telkom Purwokerto \\ Jl.D.I.Panjaitan, No. 128, Purwokerto 53147, Jawa Tengah, Indonesia \\ 1,*Penulis korespondensi: 16101024@ittelkom-pwt.ac.id \\ ${ }^{2}$ sevia@ittelkom-pwt.ac.id
}

Received on 28-08-2020, accepted on 20-10-2020, published on 30-12-2020

Abstrak

Batik merupakan kebudayaan asli Indonesia yang diakui sebagai warisan dunia. Banyaknya industri batik menyebabkan terjadinya pencemaran lingkungan. Beberapa industri terkadang tidak melakukan pengelolaan air limbah sesuai dengan standar yang ditetapkan. Penduduk sekitar dan pihak pemerintah setempat perlu melakukan monitoring terhadap pengelolaan air limbah dengan memanfaatkan teknologi terbaru. Salah satu standar untuk menentukan kualitas air adalah suhu, kekeruhan dan tingkat pH. Sistem monitoring air limbah batik merupakan alat yang digunakan untuk memantau parameter-parameter tersebut sehingga air batik tersebut bisa ditentukan apakah sudah layak untuk dibuang langsung ke sungai atau belum. Pada penelitian ini akan menggunakan tiga sensor untuk mengukur parameter-parameter penentu kualitas air yaitu sensor suhu air waterproof DS18B20, sensor kekeruhan SEN0189, dan pH meter SEN0161. Sistem ini bekerja dengan cara mengukur parameter-parameter tersebut lalu mengirimnya ke dalam platform internet of thing (ThingSpeak) dengan menggunakan komunikasi LoRa. Dari hasil pengujian prototype tersebut diperoleh nilai eror sensor PH4502C sebesar $2.10 \%$, sensor kekeruhan SEN0189 sebesar $1.24 \%$ dan sensor suhu DS18B20 6,79\%.

Kata kunci: Limbah Batik, LoRa Communication, Sensor DS18B20, Sensor PH4502C, Sensor SEN0189.

\section{Abstract}

Batik is a native Indonesian culture which recognized as a world heritage. The number of batik industries causes environmental pollution. Some industries sometimes do not carry out wastewater management by established standards. Therefore, the residents and governments need to monitor wastewater management by utilizing the latest technology. One of the standards to determine water quality is temperature, turbidity, and pH level. The batik wastewater monitoring system is a tool used to monitor these parameters so that the batik water can be determined whether it is feasible to be discharged directly into the river or not. In this study, three sensors will be used to measure the parameters that determine water quality, namely the DS18B20 waterproof water temperature sensor, SEN0189 turbidity sensor, and SEN0161 pH meter. This system works by measuring these parameters and then sending them into the internet of things (ThingSpeak) platform using LoRa communication. From the prototype test results, the PH4502C sensor error value is $2.10 \%$, the SEN0189 turbidity sensor is $1.24 \%$, and the DS18B20 temperature sensor is $6.79 \%$. 
Keywords: Wastewater of batik industry, LoRa Communication, DS18B20 Sensor, PH4502C Sensor, SEN0189 Sensor

\section{Pendahuluan}

Batik merupakan warisan kebudayaan Indonesia dalam bentuk kerajinan tekstil. Batik diakui Badan Perserikatan Bangsa-Bangsa Urusan Kebudayaan (UNESCO) sebagai warisan budaya yang berasal dari Indonesia[1]. Pengakuan ini diberikan UNESCO dengan melihat berbagai upaya yang dilakukan oleh Indonesia, terutama karena penilaian terhadap keragaman motif batik yang penuh makna filosof mendalam. Banyaknya industri batik ini berdampak buruk khususnya pada lingkungan. Industri-industri batik terkadang tidak melakukan pengolahan air limbah batik sesuai standar yang telah ditentukan. Limbah batik terus mencemari air maupun tanah dan hal ini menimbulkan keprihatinan khususnya warga setempat[2]. Cara mengatasi permasalahan tersebut pemerintah menerbitkan Perda Nomor 5 Tahun 2012 tentang Baku Mutu Lingkungan (BML). Pemerintah juga membuat tempat untuk mengolah limbah air batik (IPAL) untuk mengolah limbah tersebut sebelum dibuang agar tidak mencemari lingkungan. Pemerintah juga memonitor limbah secara manual dan berkala dengan mengecek parameter air limbah tersebut. Sebuah sistem baru yang bisa memantau pembuangan air limbah di kawasan instalasi pengolahan air limbah (IPAL) diperlukan. LoRa adalah teknologi baru yang menawarkan jangkauan komunikasi yang tinggi dan energi yang rendah, sehingga efektif untuk merancang sebuah sistem pemantauan limbah batik[3].

Air yang bermanfaat bagi manusia diperlukan parameter atau ukuran yang dapat menentukan kualitas air. Parameter kualitas air antara lain tingkat kekeruhan, suhu, dan tingkat $\mathrm{pH}$. Ketiga parameter tersebut merupakan informasi yang sangat penting untuk diketahui dalam penentuan kualitas air dalam dunia industri. Parameter $\mathrm{pH}$ merupakan parameter yang paling penting karena dibalik $\mathrm{pH}$ pada air limbah yang tidak sesuai dengan baku mutu mengindikasikan adanya zat-zat yang berbahaya di dalamnya sehingga apabila dibuang langsung tanpa diolah dapat merusak lingkungan dan ekosistem[4]. Parameter kedua adalah kekeruhan, parameter ini erat kaitannya dengan total suspended solid (TSS), air dikatakan keruh apabila air tersebut mengandung begitu banyak partikel bahan yang tersuspensi sehingga memberikan warna/rupa yang berlumpur dan kotor sehingga mengindikasikan didalamnya terdapat zat-zat yang berbahaya[5]. Parameter ketiga adalah suhu, parameter ini ada keterhubungannya dengan kadar Dissolved Oxygen (DO) dalam air. Semakin besar nilai DO pada air, mengindikasikan air tersebut memiliki kualitas yang bagus. Sebaliknya jika nilai DO rendah, dapat diketahui bahwa air tersebut telah tercemar. Kualitas air dapat diketahui dengan menggunakan sensor, kemudian data dari sensor dapat dikirimkan ke penanggung jawab lingkungan melalui internet agar segera ditangani.

Internet of things adalah infrastruktur global untuk masyarakat dalam menyampaikan informasi, memungkinkan layanan yang canggih, dengan menghubungkan objek (things) baik fisik maupun virtual berdasarkan teknologi pertukaran informasi saat ini dan perkembangannya serta teknologi komunikasi[6]. Platform ini dimanfaatkan sebagai media kirim untuk memantau suhu, tingkat $\mathrm{pH}$, dan kekeruhan air limbah batik. Sistem ini bekerja dengan cara mengukur beberapa parameter diatas dengan menggunakan tiga sensor yaitu sensor suhu DS18B20, tingkat kekeruhan SEN0189 dan tingkat pH PH4502C, kemudian dikirim melalui LoRa ke dalam platform internet of things (IoT) ThingSpeak sehingga dapat dipantau apakah limbah tersebut sudah memenuhi syarat untuk dibuang langsung atau tidak[5].

\section{Metode Penelitian}

Metode yang digunakan pada penelitian ini adalah Analitik Implementative (development) dan eksperimental, yaitu sebuah proses penelitian yang melibatkan pembuatan perangkat lunak dan perangkat keras sesusai dengan tujuan penelitian.

Tahap awal dari penelitian ini adalah studi literatur, pada tahap ini peneliti mencari informasi guna untuk mendukung penelitian. Sumber yang digunakan yaitu jurnal ilmiah, prosiding, buku dan lainnya. Studi literatur berfungsi sebagai pemberi referensi sehingga dapat menemukan konsep sebagai penelitian.

Tahap kedua adalah perancangan sistem, pada tahap ini merupakan pembuatan alat yang akan digunakan. Pada tahap ini semua komponen yang ada akan dirangkai menjadi sebuah sistem monitoring 
air limbah batik. Komponen yang digunakan antara lain tiga buah sensor DS18B20, PH45012C, SEN0189 mikrokontroler Arduino uno, dan LoRa sebagai komunikasinya.

Tahap ketiga merupakan penyusunan program. Pada tahap ini script program akan disusun sebagai perintah untuk menjalankan mikrokontroler Arduino uno. Penyusunan script program ini menggunakan software Arduino IDE.

Tahap ke-empat yaitu proses implementasi, pada tahap ini script program akan diterapkan pada Arduino uno. Dalam tahap ini akan diketahui apakah script program yang dirancang berhasil atau tidak. Apabila script program berhasil maka bisa dilanjutkan ketahap selanjutnya sedangkan jika gagal maka script program tersebut akan disusun kembali untuk diperbaiki.

Tahap kelima adalah pengambilan data (suhu, tingkat kekeruhan dan tingkat $\mathrm{pH}$ ), pada tahap ini peneliti akan mengambil data langsung di lokasi industri batik. Data tersebut diambil dengan cara menaruh alat tersebut dilokasi limbah batik dan dicatat outputnya di platform ThingSpeak. Data yang akan ditampilkan berupa suhu dalam satuan $\left({ }^{\circ} \mathrm{C}\right)$, kekeruhan $(\mathrm{NTU})$, dan tingkat $\mathrm{pH}$ dari air limbah batik tersebut.

Tahapan yang ke-enam adalah tahapan analisis data. Pada tahapan ini data-data yang telah diperoleh akan diolah dan dianalisis pada sistem monitoring air limbah batik ini.

Tahap ketujuh penelitian ini adalah penarikan kesimpulan. Pada tahapan ini data yang yang telah dianalisis akan disimpulkan hasilnya. Kesimpulan ini berisi jawaban dari rumusan masalah yang telah dibuat.

\section{HASIL DAN ANALISA}

\section{A. Implementasi}

Penelitian ini digunakan untuk memantau air limbah batik pada instalasi pengelolaan air limbah (IPAL). Dalam sistem monitoring ini ada 3 parameter yang dipantau yaitu tingkat $\mathrm{pH}$, kekeruhan dan suhu. Alat yang digunakan untuk memantau parameter tersebut yaitu sensor PH4502C sebagai pendeteksi tingkat pH, SEN0189 sebagai pendeteksi tingkat kekeruhan dan DS18B20 sebagai pendeteksi suhu air limbah batik. Pemantauan ini dilakukan di hasil akhir penampungan air limbah yang telah diolah. Pemantauan ini juga sangat penting agar kualitas air limbah yang telah diolah ini sesuai standar.

\section{B. Hasil Penelitian}

Data yang ditampilkan pada platform thingspeak berjumlah 30 data dengan durasi antar data selama 16 detik. Data tersebut berisi hasil pemantauan air limbah batik yaitu tingkat $\mathrm{pH}$, kekeruhan dan suhu.

Tabel 1 Pengujian Sensor

\begin{tabular}{|c|c|}
\hline Sensor & Rata-rata error(\%) \\
\hline PH4502C & $2.10 \%$ \\
\hline SEN0189 & $1.24 \%$ \\
\hline DS18B20 & $3,60 \%$ \\
\hline
\end{tabular}

Dari hasil pengujian prototype tersebut diperoleh nilai eror sensor PH4502C sebesar 2.10\%, sensor kekeruhan SEN0189 sebesar 1.24\% dan sensor suhu DS18B20 3,6\% (Tabel 1).

\section{Hasil Perancangan Sistem}

Hasil dari perancangan sistem akan ditampilkan dalam platform thingspeak (Gambar 1). Perancangan dimulai dari perangkat end device yang menghasilkan nilai keluaran berupa hasil pembacaan sensor. Data tersebut kemudian akan diolah menggunakan Arduino uno dan dikirim oleh LoRa shield menggunakan protokol LoRa. Data tersebut dikirm ke LoRa gateway dan diteruskan ke platform thingspeak. Berikut merupakan hasil perancangan sistem secara keseluruhan. 


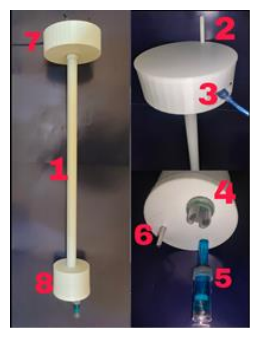

Gambar 1 Hasil Perancangan

Tabel 2 Komponen pada Gambar 1

\begin{tabular}{|c|l|l|}
\hline No & \multicolumn{1}{|c|}{ Nama } & \multicolumn{1}{c|}{ Keterangan } \\
\hline 1 & Pipa paralon & $\begin{array}{l}\text { Berfungsi untuk pelindung kabel penghubung antara tempat sensor (7) } \\
\text { dengan tempat Arduino uno dan LoRa shield (8). }\end{array}$ \\
\hline 2 & Antena & $\begin{array}{l}\text { Berfungsi untuk mentransmisikan data dari LoRa shield ke gateway } \\
\text { dragino LG01N. Antena yang digunakan dalam sistem ini adalah 3 dBi. }\end{array}$ \\
\hline 3 & Port USB & $\begin{array}{l}\text { Berfungsi sebagai jalur sumber power. Power yang digunakan berasal } \\
\text { dari powerbank dengan tengangan sebesar 5 Volt. }\end{array}$ \\
\hline 4 & Sensor SEN0189 & Berfungsi untuk mendeteksi tingkat kekeruhan air limbah batik. \\
\hline 5 & SensorPH4502C & Berfungsi untuk mendeteksi tingkat pH air limbah batik. \\
\hline 6 & Sensor DS18B20 & $\begin{array}{l}\text { Berfungsi untuk mendeteksi suhu air limbah batik, dimana } \\
\text { menggunakan satuan }\left({ }^{\circ} \mathrm{C}\right) .\end{array}$ \\
\hline 7 & Pelindung LoRa Shield & \multicolumn{1}{c}{-} \\
\hline
\end{tabular}

Setelah alat didapatkan data berupa grafik di thingspeak. Data tersebut dapat dilihat pada gambar dibawah ini.

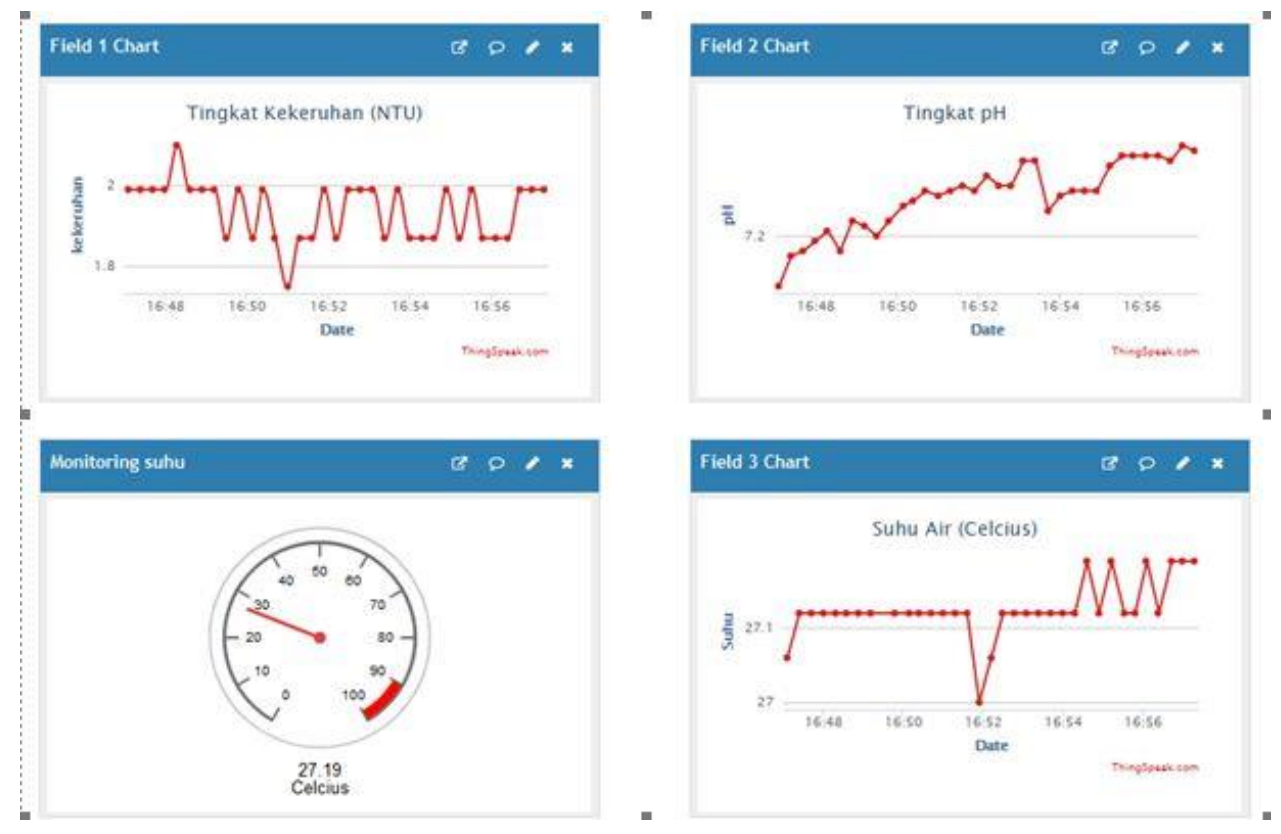

Gambar 2 Tampilan pada ThingSpeak

\section{Analisis Sensor PH4502C}

Berdasarkan pengujian sensor pH4502c terhadap tiga sampel air dengan tingkat $\mathrm{pH}$ 4.00, 6.86 dan 9.18 didapatkan hasil data berupa nilai rata-rata eror. Untuk pengujian pertama dengan air $\mathrm{pH} 4.00$ 
menghasilkan nilai rata-rata eror sebesar $1.42 \%$. untuk pengujian kedua dengan air tingkat $\mathrm{pH} 6.89$ menghasilkan nilai rata-rata eror sebesar $1.72 \%$. sedangkan untuk pengujian ketiga dengan air tingkat $\mathrm{pH}$ 9.18 menghasilkan nilai rata-rata eror sebesar 3.17\%. Ketiga hasil pengujian tersebut kemudian diambil nilai rata-ratanya untuk mendapatkan total rat-rata eror sensor dengan cara menjumlahkan dan membaginya dengan jumlah banyaknya nilai yaitu 3, sehingga menghasilkan nilai total rata-rata eror sensor sebesar 2.10\%. Dengan demikian sensor pH4502c dapat dikatakan mampu untuk mendeteksi tingkat $\mathrm{pH}$ air karena berdasarkan hasil pengujian nilai rata-rata erornya berada diambang batas baik.

\section{E. Analisis Sensor SE0189}

Dari hasil pengujian tersebut diperoleh data yaitu air jernih memiliki tingkat kekeruhan sebesar 1.48 NTU, air sari jeruk memiliki tingkat kekeruhan sebesar 15,01 NTU dan air kopi memiliki tingkat kekeruhan sebesar 76,38 NTU. Sehingga dapat disimpulkan bahwa sensor SEN0189 ini mampun untuk membaca tingkat kekeruhan air dan dapat digunakan untuk membaca tingkat kekeruhan air limbah batik.

\section{F. Analisis Sensor DS18B20}

Dari pengujian sensor DS18B20 terhadap tiga jenis air dengan tingkat yang berbeda dapat diperoleh nilai rata-rata total eror. Dari pengujian pertama terhadap suhu air $11,6^{\circ} \mathrm{C}$ didapat nilai error sebesar $3.49 \%$. pengujian kedua dengan menggunakan suhu air $28,8^{\circ} \mathrm{C}$ didapat nilai eror sebesar $6,79 \%$. Dan pengujian ketiga dengan menggunakan suhu air $70,5^{\circ} \mathrm{C}$ didapatkan nilai eror sebesar $0,53 \%$. Dari tiga pengujian tersebut kemudian diambil nilai rata-rata eror dengan cara menjumlah dan membagi 3 maka didapatkan nilai total rata-rata error sebesar 3,6\%. Jadi dapat disimpulkan bahwa sensor DS18B20 ini dikatakan mampu untuk membaca suhu air dengan akurat.

\section{G. Pengujian LoRa}

Pengujian pertama LoRa dengan jarak 100 meter dengan pengiriman data sebanyak 30 data paket. Dalam pengujian tersebut didapatkan nilai tertinggi pada angka $-91 \mathrm{dBm}$ yang ditunjukkan pada pengiriman data ke-1 dan angka terendah $-105 \mathrm{dBm}$ pada pengiriman data ke-3. Namun jika dihitung secara rata-rata hasilnya $-95.23 \mathrm{dBm}$. sementara itu nilai SNR tertinggi terjadi pada pengiriman data pertama, ke-8 dan ke-15 dimana nilainya menunjukkan $11.5 \mathrm{~dB}$, sementara itu nilai SNR terendah didapatkan pada saat pengiriman data ke-27 dengan nilai $4.5 \mathrm{~dB}$

Pengujian kedua dengan jarak 200 meter dengan pengiriman data sebanyak 30 data paket. Dalam grafik tersebut terlihat bahwa nilai tertinggi pada angka $-94 \mathrm{dBm}$ yang ditunjukkan pada pengiriman data ke-6 dan angka terendah $-100 \mathrm{dBm}$ pada pengiriman data ke-2. Namun jika dihitung secara rata-rata hasilnya 96.76dBm. untuk nilai SNR mulai dari pengiriman data pertama sampai terakhir tidak stabil. Nilai SNR tertinggi terjadi pada pengiriman data pertama, dimana nilainya menunjukkan $11.25 \mathrm{~dB}$, sementara itu nilai SNR terendah didapatkan pada saat pengiriman data ke- 8 dengan nilai $3.5 \mathrm{~dB}$. namun untuk nilai rata-rata SNR dari pengiriman data pada jarak 200 meter ini $8.87 \mathrm{~dB}$.

Pengujian ketiga dengan jarak 400 meter dengan pengiriman data sebanyak 30 data paket. Dalam grafik tersebut terlihat bahwa nilai tertinggi pada angka $-104 \mathrm{dBm}$ yang ditunjukkan pada pengiriman data ke-16 dan angka terendah $-111 \mathrm{dBm}$ pada pengiriman data ke-11. Namun jika dihitung secara rata-rata hasilnya $108.13 \mathrm{dBm}$. sementara itu nilai SNR tertinggi terjadi pada pengiriman data ke-8, dimana nilainya menunjukkan $2.75 \mathrm{~dB}$, sementara itu nilai SNR terendah didapatkan pada saat pengiriman data pertama dengan nilai $-109 \mathrm{~dB}$. namun untuk nilai rata-rata SNR dari pengiriman data pada jarak 200 meter ini $1.97 \mathrm{~dB}$

Pengujian terakhir menggunakan jarak maksimum pada peneliti diperoleh hasil 760 Meter. Skema dari pengujian tahap ini dilakukan dengan membawa LoRa gateway menjauhi end device dan dimulai pada jarak 400 Meter. Dalam pengujian jarak maksimum ini packet mulai loss data pada jarak sekitar 450 Meter, namun data masih masuk. Sementara itu packet mulai full loss data atau tidak ada paket yang masuk lagi pada jarak 760 Meter. 


\section{KESIMPULAN}

Cara merancang sistem monitoring tingkat $\mathrm{pH}$, kekeruhan dan suhu air limbah batik berbasis LoRa dimulai dari perancangan end device, mengatur LoRa gateway dan menghubungkannya ke platform ThingSpeak. Air limbah batik sebelum diolah mempunyai parameter tingkat $\mathrm{pH}$ sebesar 6.42, kekeruhan sebesar $20,39 \mathrm{NTU}$ dan suhu $24,79^{\circ} \mathrm{C}$. Sedangkan air limbah batik yang telah diolah mempunya parameter tingkat $\mathrm{pH}$ sebesar 7.13 , kekeruhan sebesar $3.16 \mathrm{NTU}$ dan suhu $26.13^{\circ} \mathrm{C}$. Nilai RSSI yang dihasilkan pada jarak 100 meter sebesar $-95.23 \mathrm{dBm}$ dan nilai SNR sebesar 9.94dB, nilai RSSI yang dihasilkan pada jarak 200 meter sebesar $-96.76 \mathrm{dBm}$ dan nilai SNR sebesar $8.87 \mathrm{~dB}$, nilai RSSI yang dihasilkan pada jarak 400 meter sebesar $-108.13 \mathrm{dBm}$ dan nilai SNR sebesar -1.97dB. Jarak Maksimum LoRa terhadap pengujian ialah sebesar $760 \mathrm{~m}$, Semakin jauh jarak data yang dikirim akan mempengaruhi nilai QoS LoRa.

\section{REFERENSI}

[1] A. S. Achmad Wildan, Ebta Narasukma Anggraeny, "Pengolahan Limbah Batik Dengan Metode Fotokatalitik Di Desa Gemawang Kabupaten Semarang."

[2] A. C. Cahyaningtyas, T. Yuwono, N. Marlina, And J. H. Soedarto, "Kerjasama Pemerintah Dengan Pihak Swasta, Masyarakat Dan Antar Pemerintah Dalam Penanganan Pencemaran Limbah Batik Di Kota Pekalongan Pada Tahun 2015," P. 15.

[3] L. Indrayani, "Pengolahan Limbah Cair Industri Batik Sebagai Salah Satu Percontohan Ipal Batik Di Yogyakarta," Ejes, Vol. 12, No. 2, P. 173, Nov. 2018, Doi: 10.24843/Ejes.2018.V12.I02.P07.

[4] A. Augustin, J. Yi, T. Clausen, And W. Townsley, "A Study Of Lora: Long Range \& Low Power Networks For The Internet Of Things," Sensors, Vol. 16, No. 9, P. 1466, Sep. 2016, Doi: 10.3390/S16091466.

[5] E. D. Widianto, M. S. M. Pakpahan, A. A. Faizal, And R. Septiana, "Lora Qos Performance Analysis On Various Spreading Factor In Indonesia,” In 2018 International Symposium On Electronics And Smart Devices (Isesd), Bandung, Oct. 2018, Pp. 15, Doi: 10.1109/Isesd.2018.8605471.

[6] L. Indrayani, "Pengolahan Limbah Cair Industri Batik Sebagai Salah Satu Percontohan Ipal Batik Di Yogyakarta," Ejes, Vol. 12, No. 2, P. 173, Nov. 2018, Doi: 10.24843/Ejes.2018.V12.I02.P07. 